\title{
A comparison of supraglottic devices in pediatric patients
}

This article was published in the following Dove Press journal:

Medical Devices: Evidence and Research

\author{
Senthil G Krishna ${ }^{1,2}$ \\ Faizaan Syed' \\ Mohammed Hakim' \\ Mumin Hakim ${ }^{3}$ \\ Dmitry Tumin' \\ Giorgio C Veneziano ${ }^{1,2}$ \\ Joseph D Tobias ${ }^{1,2}$ \\ 'Department of Anesthesiology \& \\ Pain Medicine, Nationwide Children's \\ Hospital, Columbus, OH, USA; \\ 2Department of Anesthesiology \& Pain \\ Medicine, The Ohio State University \\ College of Medicine, Columbus, \\ $\mathrm{OH}$, USA; ${ }^{3}$ Department of Surgery, \\ Montefiore Medical Centre, Bronx, \\ NY, USA
}

Background: When managing patients with a difficult airway, supraglottic airways (SGAs) have been used as rescue devices or to serve as a conduit for endotracheal intubation. The current study compares various clinical outcomes, including the bronchoscopic view of the glottis when using 2 SGAs, the Air-Q ${ }^{\circledR}$ laryngeal mask airway (LMA) and the i-gel ${ }^{\circledR}$ SGA, in pediatric patients.

Methods: Patients $\leq 18$ years of age were prospectively randomized to receive either the Air$\mathrm{Q}^{\circledR}$ LMA or the i-gel ${ }^{\circledR}$ SGA. Following SGA placement, a flexible fiberoptic bronchoscope was inserted through the SGA to visualize the glottis. Time taken to obtain the bronchoscopic view and place the SGA, and the ability to seal the airway at $20 \mathrm{cmH}_{2} \mathrm{O}$ were compared. The bronchoscopic view obtained was graded as follows: 1) glottic aperture seen completely; 2) glottic aperture seen partially with visual obstruction $<50 \% ; 3$ ) glottic aperture seen, but visual obstruction $>50 \%$; and 4) glottic aperture not seen.

Results: Fifty patients were enrolled and 48 (22/26 male/female) were included in the analysis. Median age was 13 years (IQR: 7, 16) and median weight was $49 \mathrm{~kg}$ (IQR: 25, 70). The Air$\mathrm{Q}^{\circledR}$ LMA and i-gel ${ }^{\circledR}$ SGA groups did not differ in device placement time (median of 19 vs 21 seconds; $95 \% \mathrm{CI}$ of difference in medians: -2 to $7 ; P=0.331$ ), the time to achieve fiberoptic view of the glottis (median of 25 vs 21 seconds; $95 \%$ CI of difference: -9 to $8 ; P=0.489$ ) or the grade of the bronchoscopic view of the airway. Eight Air- $Q^{\circledR}$ and 6 i-gel ${ }^{\circledR}$ supraglottic devices sealed the airway at $20 \mathrm{cmH}_{2} \mathrm{O}$.

Discussion: The time required for successful placement of the SGA, the time required for bronchoscopic view, and the quality of bronchoscopic view through the Air- ${ }^{\circledR}$ LMA and the i-gel ${ }^{\circledR}$ SGA did not differ.

Keywords: supraglottic airways, bronchoscopic view, glottic aperture

\section{Introduction}

A difficult airway is generally defined as a challenging situation where there is an inability or difficulty in establishing bag-mask ventilation or difficulty with conventional direct laryngoscopy. ${ }^{1}$ This presents an even greater challenge in children compared with adults due to certain anatomical variations and physiologic considerations. Hence, in children, there may be less time available resulting in an increased incidence of clinical deterioration prior to re-establishing oxygenation and ventilation. ${ }^{2}$ The most common complication associated with management of the difficult airway is transient hypoxemia; however, the most common severe complication in a failed airway is cardiac arrest. $^{3}$ Supraglottic airways (SGAs) have been used successfully in the management of difficult airways in either re-establishing and maintaining oxygenation and ventilation or as a conduit for fiberoptic-guided endotracheal intubation. ${ }^{1}$ SGAs can also
Correspondence: Senthil G Krishna Department of Anesthesiology \& Pain Medicine, Nationwide Children's Hospital, 700 Children's Drive,

Columbus, OH 43205, USA

$\mathrm{Tel}+\mathrm{l} 6147224096$

Fax +I 6147224203

Email senthil.krishna@

nationwidechildrens.org 
overcome upper airway obstruction and maintain an airway without the need for endotracheal intubation. ${ }^{1,4}$

Although various SGAs have been used as rescue airway devices, data on the relative performance of SGAs remain limited in terms of which SGA may be a preferred choice in pediatric patients with a difficult airway. Jagannathan et al compared the Air- $\mathrm{Q}^{\circledR}$ laryngeal mask airway (LMA) with the i-gel ${ }^{\circledR}$ SGA and found that they both were equally effective in providing an adequate fiberoptic view when placed by trainees, but more problems were encountered during removal of the i-gel ${ }^{\circledR}$ SGA, including dislodgement of the endotracheal tube (ETT). ${ }^{5}$ By contrast, Kim et al reported that the Air- $\mathrm{Q}^{\circledR}$ LMA provided an improved fiberoptic view over the i-gel ${ }^{\circledR}$ SGA although the i-gel ${ }^{\circledR}$ SGA was easier to place. ${ }^{6}$

Given this ambiguity over the relative utility of the 2 devices in the aforementioned studies, and variability in the results using other SGAs, ${ }^{5-13}$ we chose to compare the ease of placement, adequacy of ventilation, and the bronchoscopic fiberoptic view through the internal lumen of the Air- $Q^{\circledR}$ LMA and the i-gel ${ }^{\circledR}$ SGA in pediatric patients. By examining the fiberoptic view through these 2 devices, we sought to determine which SGA would provide a clear pathway to the glottic aperture and therefore, potentially provide an easier path for endotracheal intubation.

\section{Methods}

The study was approved by the Institutional Review Board (IRB) of Nationwide Children's Hospital with a waiver of individual consent (IRB15-00486) as both types of SGAs were accepted standard clinical practice. The trial was registered with ClinicalTrials.gov (NCT02532465). American Society of Anesthesiologists grade 1 or 2 patients who were $\leq 18$ years of age and scheduled to receive an SGA as part of standard anesthetic care for elective surgery were enrolled and randomized to receive 1 of 2 types of SGA devices: the Air-Q ${ }^{\circledR}$ LMA or the i-gel ${ }^{\circledR}$ SGA. Patients with a known or suspected difficult airway or a history of prior difficult placement of an SGA were excluded from the study. The SGA chosen by randomization was revealed to the investigator and the anesthetic team immediately prior to device placement. The size of the SGA was determined according to the manufacturer's recommendations based on the patient's weight.

The induction of anesthesia was achieved with $70 \% \mathrm{~N}_{2} \mathrm{O}$ in $\mathrm{O}_{2}$ and sevoflurane. Following placement of the intravenous cannula, $\mathrm{N}_{2} \mathrm{O}$ administration was terminated and anesthesia was supplemented with intravenous propofol $(2 \mathrm{mg} / \mathrm{kg})$ and fentanyl $(2 \mu \mathrm{g} / \mathrm{kg})$. The SGA was placed using a standard midline technique with neck flexion, head extension, mouth opening, and anterior displacement of the tongue. The time taken to place the SGA, defined as time from the removal of the anesthesia mask to reappearance of capnographic activity, was noted. Ease of insertion was assessed by the provider placing the SGA using a previously described subjective grading score of $1-4$ for SGAs ( $1=$ no resistance; $2=$ mild resistance; $3=$ moderate resistance; and $4=$ inability to insert the device). ${ }^{6,7,12}$ If the study SGA placement was unsuccessful, the airway was secured using an $\mathrm{Ambu}^{\circledR} \mathrm{LMA}$. Following satisfactory placement of the SGA, air was added to the cuff of the SGA if needed to achieve adequate chest movement with positive pressure ventilation. The ability to seal the airway at $20 \mathrm{cmH}_{2} \mathrm{O}$ without an audible leak was noted using the manometric stability test with a fresh gas flow at $3 \mathrm{~L} / \mathrm{min}^{14}$ Optimal position of the SGA was confirmed by auscultation and generation of an adequate tidal volume. If the ventilation was judged to be suboptimal by the clinical team, the airway was rescued using an $\mathrm{Ambu}^{\circledR}$ LMA.

After confirmation of adequate placement and ventilation, a flexible fiberoptic bronchoscope was inserted through the stem of the supraglottic device to visualize the glottic aperture. The time taken for bronchoscopy, defined as time from disconnection of the anesthetic circuit from the SGA to first visualization of the glottic aperture, was recorded. The bronchoscopic view obtained via the intubating SGA was graded using our scale developed from previously used scales: Grade 1= glottic aperture seen completely without any obstruction; Grade 2= glottic aperture seen only partially but visual obstruction is $<50 \%$; Grade $3=$ glottic aperture barely seen and visual obstruction is $>50 \%$; and Grade $4=$ glottic aperture not seen (Table 1). ${ }^{15,16}$ Complications, including bleeding, oxygen desaturation, laryngospasm, and bronchospasm, were also noted.

Categorical data were presented as counts with percentages and compared using Fisher's exact tests or chi-squared

Table I Grading of fiberoptic view of glottic aperture through supraglottic device

\begin{tabular}{ll}
\hline Glottic view grade & Description \\
\hline I & $\begin{array}{l}\text { Glottic aperture seen completely } \\
\text { without any obstruction } \\
2\end{array}$ \\
$\begin{array}{l}\text { Glottic aperture seen only partially } \\
\text { but visual obstruction is }<50 \%\end{array}$ \\
Glottic aperture barely seen and \\
visual obstruction is $>50 \%$ \\
4 & Glottic aperture invisible \\
\hline
\end{tabular}


tests, as appropriate. The primary analysis compared the fiberoptic view through the 2 different supraglottic devices. The percentage of acceptable or good views (grade 1 or 2 ) was compared with poor view (grade 3 or 4 ). Continuous data were presented as median with IQR and compared using rank-sum tests. Study enrollment was planned for 50 patients according to availability of study staff, and no a priori power analysis was performed. Data analysis was performed in Stata/IC 14.2 (StataCorp, LP, College Station, TX, USA) and 2 -tailed $P<0.05$ was considered statistically significant.

\section{Results}

Fifty patients were enrolled in the study, with 25 randomized to each group. Ages ranged from 1 to 18 years (median: 13 years, IQR: 7, 16) and weight ranged from 11 to $106 \mathrm{~kg}$ (median: $49 \mathrm{~kg}$, IQR: 25, 70). The size of the Air-Q ${ }^{\circledR}$ LMA varied from 1.5 to 4.5 and the size of the i-gel ${ }^{\circledR}$ SGA ranged from 2 to 5. Demographic characteristics for the 2 groups are summarized in Table 2. One patient in the Air- $Q^{\circledR}$ LMA group was excluded due to missing study data. Except for 1 patient in the Air- $Q^{\circledR}$ LMA group where 2 attempts were required, all SGAs were inserted on the first attempt. One patient in the i-gel ${ }^{\circledR}$ SGA group required removal of the SGA device and placement of an $\mathrm{Ambu}^{\circledR}$ LMA due to inadequate ventilation. In all other patients, placement of the SGA was judged as easy $\left(1=\right.$ no resistance). In one other case, the $\mathrm{i}$-gel ${ }^{\mathbb{R}}$ SGA was replaced with an $\mathrm{Ambu}^{\circledR}$ LMA after completion of data collection due to loss of ventilation. In another patient, the Air-Q ${ }^{\circledR}$ LMA was replaced with an $\mathrm{Ambu}^{\circledR}$ LMA after study data were obtained due to problems with placement of the esophagogastroduodenoscopy scope.

An acceptable fiberoptic view (grade 1 or 2) was attained in 20 of 24 cases in the Air-Q ${ }^{\circledR}$ LMA group and 21 of 23 in the i-gel ${ }^{\circledR}$ SGA one $\left(P=0.666 ; 1\right.$ case in the i-gel ${ }^{\circledR}$ SGA group had missing data on this outcome). Time taken to place the SGA did not significantly vary between the Air-Q ${ }^{\circledR}$ LMA and i-gel ${ }^{\circledR}$ SGA (median of 19 [IQR: 16, 20] vs 21 [IQR: 16, 29]

Table 2 Characteristics of patients enrolled in each study group

\begin{tabular}{lll}
\hline Characteristic & Air-Q $^{\circledR}$ LMA & i-gel \\
\hline Male & SGA \\
Age (years) & $12(50 \%)$ & $10(42 \%)$ \\
Weight $(\mathrm{kg})$ & $14(6,16)$ & $12(7,16)$ \\
SGA size & $50(22,70)$ & $49(26,69)$ \\
\hline
\end{tabular}

Notes: Data are listed as the median (IQR) or $\mathrm{N}(\%)$. $\mathrm{N}=24$ for both groups. Abbreviations: LMA, laryngeal mask airway; SGA, supraglottic airway. seconds; $95 \%$ CI of difference in medians: -2 to $7 ; P=0.331$ ). Likewise, time to achieve fiberoptic view of the glottis was similar between the 2 groups (median of 25 [IQR: 20, 30] vs 21 [IQR: 17, 40] seconds; 95\% CI of difference in medians: -9 to $8 ; P=0.489$ ). Eight Air-Q ${ }^{\circledR}$ LMAs and 6 i-gel ${ }^{\circledR}$ SGAs sealed the airway at $20 \mathrm{cmH}_{2} \mathrm{O}$ (Table 3).

\section{Discussion}

Adequate airway control with effective oxygenation and ventilation remain integral aspects of airway intervention regardless of the device used. Compared with adults, children have increased oxygen consumption coupled with a lower oxygen reserve thereby limiting their tolerance to apnea, and increasing the incidence of hypoxemia and its cardiovascular and hemodynamic sequelae. ${ }^{17}$ SGAs have proven to be extremely useful in these clinical scenarios, both as a means to restore oxygenation and ventilation as well as serving a conduit for the fiberoptic-guided endotracheal intubation. ${ }^{5,6}$ The current study compared the performance of 2 commonly used SGAs; the Air-Q ${ }^{\circledR}$ LMA and the i-gel ${ }^{\circledR}$ SGA.

Modifications of the Air- $Q^{\circledR}$ LMA to facilitate its use for device-guided endotracheal intubation include a shorter and curved shaft, no epiglottic grill, and a removable 15 mm airway adapter. ${ }^{18,19}$ However, we hypothesized that the design of the i-gel ${ }^{\circledR}$ SGA, including elimination of the need to inflate the cuff, integrated bite block, and the wide oval stem may improve in vivo stabilization, prevent axial rotation, and facilitate obtaining a bronchoscopic view of the glottis when compared with the Air- ${ }^{\circledR}$ LMA. Similar to the previous studies, ${ }^{5-13}$ as our goal was to objectively evaluate SGA use for fiberoptic-guided endotracheal intubation, we chose to use the fiberoptic view of the glottic aperture as one of the primary outcome measure to compare these 2 SGAs. Given concerns with the complexity of the grading scale ${ }^{15,16}$ and the design differences of the 2 devices, the current study used a simplified version to allow head-to-head comparison of the 2 SGAs based on the clinically relevant glottic view obtained with the device..$^{5,6}$

Previous studies directly comparing these 2 SGAs have provided contradictory results. ${ }^{5,6}$ Jagannathan et al compared the performance of the i-gel ${ }^{\circledR}$ SGA with the Air-Q ${ }^{\circledR}$ LMA in a cohort of 96 children, ranging in age from 1 month to 6 years with anatomically normal airways. ${ }^{5}$ The authors noted that the 2 devices were equally effective as conduits for fiberoptic-guided endotracheal intubation even when performed by trainees with limited prior experience. They determined that use of the $\mathrm{i}$-gel ${ }^{\circledR}$ SGA resulted in a faster 
Table 3 Study outcomes by group assignment

\begin{tabular}{|c|c|c|c|}
\hline Outcome & Air-Q ${ }^{\circledR}$ LMA & i-gel ${ }^{\otimes}$ SGA & $P$-value \\
\hline SGA insertion time (seconds) & $19(16,20)$ & $21(16,29)$ & 0.331 \\
\hline Airway leak pressure $\left(\mathrm{cmH}_{2} \mathrm{O}\right)^{\mathrm{a}}$ & $19(15,25)$ & $18(12,24)$ & 0.600 \\
\hline Airway sealable at $20 \mathrm{cmH}_{2} \mathrm{O}$ & $8(33 \%)$ & $6(25 \%)$ & 0.525 \\
\hline Time to achieve best fiberoptic view (seconds) & $25(20,30)$ & $21(17,40)$ & 0.489 \\
\hline \multicolumn{4}{|l|}{ Fiberoptic view grade } \\
\hline 1 & $20(83 \%)$ & $21(88 \%)$ & \\
\hline II & 0 & 0 & \\
\hline III & 2 & 2 & \\
\hline IV & 2 & 0 & \\
\hline Acceptable view (grade I-II) ${ }^{\mathrm{a}}$ & $20(83 \%)$ & $21(88 \%)$ & 0.666 \\
\hline
\end{tabular}

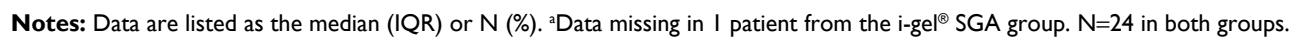

Abbreviations: LMA, laryngeal mask airway; SGA, supraglottic airway.

time to first glottic view, time to carinal view, and time to successful endotracheal intubation. However, the i-gel ${ }^{\circledR}$ SGA was associated with more problems during removal with the ETT in place, including dislodgement, need to hold downward traction, pilot balloon breakage, or inadvertent extubation. However, Kim et al in a cohort of 80 children reported that the i-gel ${ }^{\circledR}$ SGA was easier to insert with higher oropharyngeal leak pressures and lower frequencies of gastric insufflation compared with the Air-Q ${ }^{\circledR}$ LMA. ${ }^{6}$ In contrast to what was noted by Jagannathan et $a{ }^{5}{ }^{5}$ they reported that the Air-Q ${ }^{\circledR}$ LMA provided a better fiberoptic view of the glottis than the i-gel ${ }^{\circledR}$ SGA. $^{6}$

We found no clinically significant differences in the performance of the 2 devices for the tested parameters, which included their placement, function as an SGA during intraoperative care, or the fiberoptic view of the glottis that was achieved. Both SGAs were easy to place and provided a similar and acceptable view of the laryngeal structures with no difference in time required to achieve placement or glottis view. Furthermore, both devices performed similarly with respect to sealing the airway at $20 \mathrm{cmH}_{2} \mathrm{O}$. Minor airway events, which required replacement of the devices with the standard LMA that we use in clinical practice were noted in 2 patients with the i-gel ${ }^{\circledR}$ SGA (once immediately following placement and once during subsequent use) and in 1 patient with the Air- $\mathrm{Q}^{\circledR}$ LMA. Anecdotally, anesthesia providers in our department perceived the Air- $Q^{\circledR}$ LMA to be easier to use compared with the i-gel ${ }^{\circledR}$ SGA, but this subjective preference was not quantified in the present study, and not reflected in the objective measures of performance. Furthermore, our clinical practice prior to the study included sole use of the $\mathrm{Ambu}^{\circledR}$ or Air- $\mathrm{Q}^{\circledR}$ LMA thereby resulting in significant clini- cal experience with these devices as opposed to little or no prior experience with the i-gel ${ }^{\circledR}$ SGA.

With comparable performance between the devices based on our findings, the decision to favor one over the other may be influenced by other clinical factors, including the ease of advancement of the fiberoptic bronchoscope, placement of the ETT, and removal of the intubating SGA. While Jagannathan et al found no difference between the SGAs in terms of navigation of the fiberoptic bronchoscope or advancing the ETT through the device, they reported clinical problems with removal of the i-gel ${ }^{\circledR}$ SGA, including dislodgement of the ETT (see aforementioned). ${ }^{5}$ The particular feature of ease of removal of the SGA after placement of the ETT may be one factor that differentiates these 2 devices. The Air- $Q^{\circledR}$ LMA, which is designed with a large inner diameter, relatively shorter stem and detachable $15 \mathrm{~mm}$ connector piece may facilitate removal of the device following endotracheal intubation. However, this particular outcome was not specifically studied in our patient population.

Limitations of our current study include that it was not limited to a younger patient population as in previous studies, but rather enrolled the entire spectrum of pediatric ages. Although we acknowledge that younger children with associated difficult airways are relatively more challenging, we designed our study to be a representation of the patient population that we encounter in our routine clinical practice. We also limited our study to only these 2 devices, as they are the most commonly and successfully used intubating SGAs in pediatric patients. As with other studies, our cohort included patients with anatomically normal airways and may not be truly representative of the outcomes that would be achieved in patients with a difficult airway. We also did not compare 
the ease of placement of an ETT through the SGA and the ease of subsequent removal of SGA. Finally, our study was conducted with a convenience sample and therefore. may have had limited statistical power to compare rare events between the 2 SGA types, including subsequent intraoperative performance in various clinical scenarios and varying surgical procedures. With these caveats in mind, the current study adds further data comparing 2 of the most commonly used SGAs in the pediatric-aged patient. We noted that there were no clinically significant differences in the performance of the 2 devices in the tested parameters. Both devices performed equally well despite the fact that the clinical staff had limited previous experience with the i-gel ${ }^{\circledR}$ SGA, which further demonstrates that clinical expertise with placement of SGAs can be rapidly acquired. Additional studies are needed to evaluate whether previously noted problems identified during removal of the i-gel ${ }^{\circledR}$ SGA after endotracheal intubation make the Air- $Q^{\circledR}$ LMA the preferred choice of SGA for the management of the difficult airway in children.

\section{Disclosure}

The authors report no conflicts of interest in this work.

\section{References}

1. Jagannathan N, Sequera-Ramos L, Sohn L, Wallis B, Shertzer A, Schaldenbrand K. Elective use of supraglottic airway devices for primary airway management in children with difficult airways. Br J Anaesth. 2014;112(4):742-748

2. Walker RWM. Management of the difficult airway in children. $J R$ Soc Med. 2001;94(7):341-344.

3. Jagannathan N, Sohn L, Fiadjoe JE. Paediatric difficult airway management. what every anaesthetist should know! Br J Anaesth. 2016;117(Suppl 1):i3-5.

4. Kleine-Brueggeney M, Gottfried A, Nabecker S, Greif R, Book M, Theiler L. Pediatric supraglottic airway devices in clinical practice: A prospective observational study. BMC Anesthesiol. 2017;17(1):119.
5. Jagannathan N, Sohn L, Ramsey M, et al. A randomized comparison between the i-gel ${ }^{\mathrm{TM}}$ and the air- $\mathrm{Q}^{\mathrm{TM}}$ supraglottic airways when used by anesthesiology trainees as conduits for tracheal intubation in children. Can J Anaesth. 2015;62(6):587-594.

6. Kim MS, Lee JH, Han SW, Im YJ, Kang HJ, Lee JR. A randomized comparison of the i-gel with the self-pressurized air-Q intubating laryngeal airway in children. Paediatr Anaesth. 2015;25(4):405-412.

7. Lee JR, Kim MS, Kim JT, et al. A randomised trial comparing the i-gel (TM) with the LMA Classic (TM) in children. Anaesthesia. 2012;67(6):606-611.

8. Jagannathan N, Sohn LE, Sawardekar A, Gordon J, Langen KE, Anderson K. A randomised comparison of the LMA Supreme ${ }^{\mathrm{TM}}$ and LMAProSealTM in children. Anaesthesia. 2012;67(6):632-639.

9. Jagannathan N, Sohn LE, Sawardekar A, et al. A randomised comparison of the self-pressurised air-QTM intubating laryngeal airway with the LMA Unique ${ }^{\mathrm{TM}}$ in children. Anaesthesia. 2012;67(9):973-979.

10. Jagannathan N, Sohn LE, Sawardekar A, et al. A randomized trial comparing the $\mathrm{Ambu}^{(\mathbb{B}}$ Aura-i $\mathrm{i}^{\mathrm{TM}}$ with the air- $\mathrm{Q}^{\mathrm{TM}}$ intubating laryngeal airway as conduits for tracheal intubation in children. Paediatr Anaesth. 2012;22(12):1197-1204.

11. Fukuhara A, Okutani R, Oda Y. A randomized comparison of the i-gel and the ProSeal laryngeal mask airway in pediatric patients: performance and fiberoptic findings. J Anesth. 2013;27(1):1-6.

12. Kim MS, Oh JT, Min JY, Lee KH, Lee JR. A randomised comparison of the i-gel ${ }^{\mathrm{TM}}$ and the Laryngeal Mask Airway Classic ${ }^{\mathrm{TM}}$ in infants. Anaesthesia. 2014;69(4):362-367.

13. Lee YC, Yoon KS, Park SY, Choi SR, Chung CJ. A comparison of i-gel ${ }^{\mathrm{TM}}$ and Laryngeal Mask Airway Supreme ${ }^{\mathrm{TM}}$ during general anesthesia in infants. Korean J Anesthesiol. 2018;71(1):37-42.

14. Keller C, Brimacombe JR, Keller K, Morris R. Comparison of four methods for assessing airway sealing pressure with the laryngeal mask airway in adult patients. Br J Anaesth. 1999;82(2):286-287.

15. Brimacombe J, Berry A. A proposed fiber-optic scoring system to standardize the assessment of laryngeal mask airway position. Anesth Analg. 1993;76(2):457.

16. Park C, Bahk JH, Ahn WS, Do SH, Lee KH. The laryngeal mask airway in infants and children. Can J Anaesth. 2001;48(4):413-417.

17. Engelhardt T, Weiss M. A child with a difficult airway: what do I do next? Curr Opin Anaesthesiol. 2012;25(3):326-332.

18. Jagannathan N, Kho MF, Kozlowski RJ, Sohn LE, Siddiqui A, Wong DT. Retrospective audit of the air-Q intubating laryngeal airway as a conduit for tracheal intubation in pediatric patients with a difficult airway. Paediatr Anaesth. 2011;21(4):422-427.

19. Attarde VB, Kotekar N, Shetty SM. Air-Q intubating laryngeal airway: A study of the second generation supraglottic airway device. Indian $J$ Anaesth. 2016;60(5):343-348.
Medical Devices: Evidence and Research

\section{Publish your work in this journal}

Medical Devices: Evidence and Research is an international, peerreviewed, open access journal that focuses on the evidence, technology, research, and expert opinion supporting the use and application of medical devices in the diagnosis, monitoring, treatment and management of clinical conditions and physiological processes. The identification of novel

\section{Dovepress}

devices and optimal use of existing devices which will lead to improved clinical outcomes and more effective patient management and safety is a key feature. The manuscript management system is completely online and includes a quick and fair peer-review system. Visit http://www. dovepress.com/testimonials.php to read real quotes from authors. 